$\underline{\text { Case Reports }}$

\title{
A case of chronic granulomatous disease
}

\author{
G N Lucas ${ }^{1}$, S Sriranganathan ${ }^{2}$, S Gunawardene ${ }^{3}$, N R de Silva ${ }^{3}$
}

Sri Lanka Journal of Child Health, 2000; 29: 27-28

(Key words: Chronic granulomatous disease; phagocyte deficiencies)

\section{Introduction}

Chronic granulomatous disease (CGD) is an inherited disorder in which phagocytes are unable to generate reactive oxygen intermediates, such as superoxide, due to defects in gene coding for one of several components of the NADPH oxidase. Patients develop severe, recurrent infections with catalase-positive bacteria and fungi ${ }^{1}$. Frequently, CGD is inherited as an X-linked recessive disease associated with cytochrome $\mathrm{b}_{559}$ deficiency ${ }^{2}$. Affected patients have recurrent infections from infancy, usually involving the skin, lymph nodes, lungs, liver and gastrointestinal tract. These bacterial and fungal infections are responsible for early deaths ${ }^{3}$.

\section{Case report}

A one year and ten month old baby from Mannar was admitted to the Anuradhapura General Hospital in May 1999 with unresolving pneumonia. Whilst being treated there, the child developed a pneumothorax and was transferred to the cardio-thoracic unit of the National Hospital, Colombo for intercostal drainage. In June 1999, the child was transferred to the Lady Ridgeway Hospital (LRH) for further investigation.

On admission to LRH, the child had fever, cough and shortness of breath for over 2 months, accompanied by loss of weight and loss of appetite. There was no consanguinity. Two male siblings had died after developing pneumonia, one at the age of 3 months and the other at the age of 5 years.

On examination, the child was febrile and wasted with oral ulcers, hepato-splenomegaly and clubbing. There was no lymphadenopathy. There were bilateral crepitations over the lungs. Chest $\mathrm{x}$-ray showed bilateral pneumatocoeles. After 2 weeks of therapy with ceftriaxone, cloxacillin and netilmycin, there was marked improvement in the clinical signs and chest x-ray.

${ }^{1}$ Paediatrician, ${ }^{2}$ Senior Registrar, Lady Ridgeway Hospital, Colombo. ${ }^{3}$ Medical Officer, Department of Immunology, Medical Research Institute, Colombo.
The ESR was $133 \mathrm{~mm}$ in the first hour and the haemoglobin was $9.4 \mathrm{~g} / \mathrm{dI}$. The total white cell count was $10.4 \times 10^{9} / \mathrm{L}$ (N 59\%, L 36\%, E 4\%, M 1\%). The peripheral blood film showed a moderate neutrophil leucocytosis and a hypochromic, microcytic anaemia. Serum immunoglobulin levels were as follows - IgG $2378 \mathrm{mg} / \mathrm{dl}$ (normal range 258-1393), IgA $200 \mathrm{mg} / \mathrm{dl}$ (normal range 19-119), IgM 290 mg/dl (normal range 14-114). Neutrophils from the patient did not exhibit dye reduction with the nitroblue tetrazolium (NBT) test. However, the myeloperoxidase activity of neutrophils was normal. Based on these findings, a diagnosis of chronic granulomatous disease (CGD) was made and the child was started on long term cotrimoxazole prophylaxis. This is the first laboratory confirmed case of CGD in Sri Lanka.

\section{Discussion}

Reduction of nitroblue tetrazolium (NBT) dye is the standard method for detecting defective oxidative metabolism and making the diagnosis of $\mathrm{CGD}^{4}$. Phagocytes from patients with CGD fail to generate any superoxide anion during phagocytosis and are unable to reduce NBT. Neutrophil leucocytosis, hypochromic microcytic anaemia, elevated ESR and increased serum immunoglobulin concentrations found in our patient merely reflect response to chronic infection. The most common catalasepositive organism causing infection in CGD is Staphylococcus aureus which accounts for about $40 \%$ of clinical infection isolates. Other catalasepositive organisms include Escherichia coli, Klebsiella, Enterobacter, Serratia marescens, Salmonella and Pseudomonas species which account for an additional $30 \%$ of infections. Yeast and fungi, particularly Aspergillus, account for another 30\% of isolates ${ }^{3}$. Bacterial prophylaxis with a daily antistaphylococcal agent has been demonstrated to reduce significantly the incidence of bacterial infections 5 . Common catalase-negative organisms such as Streptococcus pneumoniae and Haemophilus influenzae do not usually cause problems because they release into phagocytic vacuoles small amounts 
of hydrogen peroxide that is used by the CGD phagocyte to kill these bacteria.

\section{References}

1. Abramson S L. Phagocyte Deficiencies. In rich R R, Fleisher T A, Schwartz B D, Shearer W T, Strober W, (eds). Clinical Immunology Principles and Practice, USA: Mosby, 1996; 682-6.

2. Dinauer M C, Orkin S H, Brown R, Jesaitis A J, Parkos C A. The glycoprotein encoded by the Xlinked chronic granulomatous disease locus is a component of the neutrophil cytochrome $b$ complex. Nature 1987; 327:717.
3. Gallin J I, Buesher E S, Seligmann B E. Recentadvancesin chronic granulomatous diseases. Annals of Internal Medicine 1983; 99: 657.

4. Ewel C H, Kuhns D B, Keller J R. Clinical monitoring of imune and haemopoietic functions. In Rose N R, de Macario E C, Fahey J L, Friedman H, Penn G M (eds). Manual of Clinical Laboratory Immunology. 4th ed. Washington: American Society of Microbiology, 1992; 929-30.

5. Margolis D M, Melnick D A, Ailing D W. Trimethoprim-sulfamethoxazole prophylaxis in the management of chronic granulomatous dosease. Journal of Infectious Diseases, 1990; 723:162. 
